\title{
Effect of Thermal Embryonic Manipulation on the Quality of Male and Female Broiler Meat Submitted to Thermal Stress Pre-Slaughter
}

-Author(s)

\section{Fernandes JIM}

Santos TC"

Kaneko IN"

Horn D'

Leyter JR'

Pasa $C B^{\prime}$

Laboratory of Poultry Experimentation Federal University of Parana - Palotina, 85950-000, Parana, Brazil.

" Department of Animal Science, State University of Maringa, 87020-900, Parana, Brazil.

\section{ABSTRACT}

Adverse environmental conditions during rearing may negatively affect productivity and meat quality of the modern fast-growing broiler strains. Temperature manipulation during sensitive embryonic development periods may affect broilers' physiological responses to environmental conditions during rearing on commercial farms. The objective of this trial was to evaluate the effect of temperature manipulation during incubation and breeder age on the meat quality of male and female broilers submitted to heat stress during the preslaughter period. In this experiment, 1280 broiler chicks were distributed according to a completely randomized experimental design in a $2 \times 2 \times 2$ factorial arrangement. Treatments consisted of two breeder ages (30 and 60 weeks), two temperature programs applied in the last four days of incubation (standard or high temperature), and sex (male and female). Birds were submitted to $32{ }^{\circ} \mathrm{C}$ for 48 hours before slaughter, on day 46.Meat quality parameters ( $\mathrm{pH}$, temperature, color, and weight loss) were evaluated. There was significant effect $(p<0.05)$ of sex on meat redness $\left(a^{*}\right)$ and fat percentage, with females presenting higher values than males in both measurements. Males incubated at the higher temperature presented higher $(p<0.05)$ meat weight loss by pressure than females. The thermal manipulation applied during the final stage of incubation did not affect the meat yield or meat quality of broilers submitted to heat stress.

\section{INTRODUCTION}

Extreme environmental conditions may pose serious challenges for modern broiler strains genetically selected for fast growth (Yahav et al., 2004). Heat stress is one of the factors that causes performance losses in the poultry industry. When environmental temperature exceeds the comfortable temperature range, broilers reduce their feed intake and spend energy to dissipate heat in order to maintain homeothermia, resulting in poor performance (McKee \& Sams, 1997) and meat quality defects. Heat stress increases the need of energy production via anaerobic glycolytic processes, with consequent production of lactic acid (Berri et al., 2005). The combination of low meat pH due to high lactic acid content with high meat temperature causes muscle protein denaturation, thereby, reducing meat protein stability and water retention capacity (Berri et al., 2005; Collin et al., 2007).

A meat quality defect, consisting of the presence of several degrees of white striping on the breasts of broilers, which follow the direction of the muscle fibers, has been recently reported. The incidence of the defect increases with age (Petracci \& Cavani, 2011). Although its cause has not been elucidated yet, it is possible that the fast development of broilers, in association with inadequate environmental conditions may be contributing factors. This supports the need to search for 
Fernandes JIM, Santos TC, Kaneko IN, Horn D, Leyter JR, Pasa CLB
Effect of Thermal Embryonic Manipulation on the Quality of Male and Female Broiler Meat Submitted to Thermal Stress Pre-Slaughter alternatives that effectively reduce the impacts of high environmental temperatures on broiler performance (Collin et al., 2007).

As a consequence, if the higher growth rate of modern broilers, the proportion between pre- and post egg-hatching life periods was reduced to less than 1:1.5. Therefore, the development of their thermoregulatory system, which controls body temperature during the incubation phase, needs to be better understood, as well as to how to induce acclimation to adverse environmental conditions during the post egg-hatching period.

A protocol of single-stage incubation that includes periodic stimuli, which consists of increasing temperatures during specific sensitive periods of embryonic development, has been applied and it is referred as circadian incubation. It is believed that slight incubation environment variations induce variations in gene expression; as a result, different phenotypes are expressed according to environmental agents (Boerjan, 2010). The most sensitive period in the development of the embryonic thermoregulatory system is during the last days of incubation. During this period, some factors, such as incubation temperature, may induce changes in the perinatal epigenetic programming of body functions (Tzschentke \& Plageman, 2006).

Many studies have focused on intermittent temperature manipulation during incubation, ranging from 3 to 12 hours per day and deviating $1-2^{\circ} \mathrm{C}$ from standard incubation temperature, with very variable results (Moraes et al., 2004; Yalçin \& Siegel, 2003; Collin et al., 2005; Yalçin et al., 2005; Collin et al., 2007; Yalçin et al., 2008; Piestun et al., 2008, Ferreira et al., 2015). For instance, Tzschentke \& Halle (2009) increased the incubation temperature from $38.2^{\circ} \mathrm{C}$ to $38.4^{\circ} \mathrm{C}$ for two hours daily between days 18 and 21 of incubation and observed greater body weight in male broilers at slaughter age. Today, it is difficult to reach consensus relative to protocols for the manipulation of the incubation environment of broiler embryos at industrial level to try to improve live performance in the field (Boerjan, 2010).

Another issue is whether the development of the broilers' metabolic functions can be improved by shorttime temperature stimuli. The development of all tissues is affected by incubation temperature, suggesting that embryonic development can be manipulated and may allow pre-conditioning broiler embryo metabolism to post-hatching environmental conditions (Aksitet al., 2010; Molenaar et al., 2010). Some authors show, for instance, that broiler muscle development can be stimulated by temperature changes at different incubation stages, such as Maltby et al. (2004) during initial phase of incubation, Halevyet al. (2006) between day 16 and 18,or during the first days posthatching (Halevy et al., 2001). According to Collin et al. (2007), incubation temperature manipulations may allow broilers to cope with environmental temperature changes without spending energy, and therefore, to obtain good post-hatching performance. However, temperature stimuli must be applied during the last days of incubation. Currently, new investigations are being conducted to define the maximum intensity and length of temperature stimuli for different types of eggs (Boerjan, 2010).

In addition of varying with genetic selection and embryonic development stage, heat production depends on embryo size, which is determined by broiler breeder age. Hamidu et al. (2007) found that the metabolism of embryos from smaller eggs laid by young breeder hens is slower because they receive oxygen lower supply as a result of their thicker shells relative to eggs laid by older breeders. Oxygen is the fuel used for the beta-oxidation of fatty acids in the egg yolk, affecting the embryos' metabolic rate or heat production (Molenaar et al., 2010).

Therefore, the aim of this study was to evaluate the effects of incubation temperature manipulation and breeder age of breeders on the meat quality of male and female broilers submitted to heat stress during the pre-slaughter period.

\section{MATERIALS AND METHODS}

In total 1,280 eggs were distributed in the hatchery according to a completely randomized design in a $2 \mathrm{x}$ $2 \times 2$ factorial arrangement, consisting of two breeder ages (30 and 60 weeks), two temperatures applied during the last four days of incubation $\left(37.2-37.4^{\circ} \mathrm{C}\right.$ and $38.2-38.4^{\circ} \mathrm{C}$ for 4 hours/d), and sex (males and females), resulting in eight treatments with four replicated of 40 eggs each. Eggs were incubated in single-stage incubator (James Way, model Platinum) at $96.5-100.4^{\circ} \mathrm{F}, 40 \%$ relative humidity (RH), and 10,000 ppm $\mathrm{CO}_{2}$ until day 10 and 5,000 ppm $\mathrm{CO}_{2}$ from day 11 to day 21 of incubation.

After hatch, birds were reared in the experimental poultry house of the Federal University of Parana, Palotina, PR, Brazil. The environmentally-controlled broiler house was equipped with evaporative cooling pads and 15-m length and 12-m width vents, divided into 32 pens measuring $3.75 \mathrm{~m} 2$. Water and a commercial feed were supplied ad libitum. A five-phase 
feeding program was applied: pre-starter $(23.30 \%$ CP, $3,000 \mathrm{kcal} \mathrm{ME} / \mathrm{kg}, 1.25 \%$ Lys), starter I $(23.00 \%$ CP, $3,100 \mathrm{kcal} \mathrm{ME} / \mathrm{kg}, 1.250 \%$ Lys), starter II $(22.12 \%$ CP, $3,150 \mathrm{kcal} \mathrm{ME} / \mathrm{kg}, 1.2 \%$ Lys), grower $(21.25 \%$ CP, $3,200 \mathrm{kcal} \mathrm{ME} / \mathrm{kg}, 1.16 \% \mathrm{Lys})$, and finisher $(20.25 \%$ CP, 3,280kcal ME/kg, 1.111\% Lys).

From day 1 to 44 , house temperature was maintained in the thermal neutral zone, according to the strain's management guide (Cobb, 2008). On day 44 , house temperature was increased up to $32^{\circ} \mathrm{C}$ and fan speed was decreased $(1.5 \mathrm{~m} / \mathrm{sec})$ for 48 hours.

On day 46, eight birds per treatment were individually weighed and sacrificed, and their carcasses were used to evaluate meat quality in the Laboratory of Poultry Experimentation of UFPR. Birds were bled, and their carcasses were scalded, plucked, and eviscerated. Carcass yield was calculated as the ratio between hot eviscerated carcass and live body weight. Prime cut yields (whole breast, thigh and legs, with skin and bones) were calculated as their absolute weight relative to eviscerated carcass weight. Abdominal fat around the cloaca, bursa of Fabricius, gizzard, proventriculus, and adjacent abdominal muscles was removed and weighed. Abdominal fat yield was calculated as its weight relative to eviscerated carcass weight.

All breasts were assessed for the presence of white striping. Breasts without visible white striping were considered negative, whereas those presenting clearly visible whitish stripes parallel to muscle fibers on the muscle surface were classified as positive. Negative and positive percentages were calculated relative to the total number of breasts/ treatment.

The right Pectoralis major muscle (breast fillet) of each bird was identified and maintained at room temperature for $15 \mathrm{~min}$ post-mortem for $\mathrm{pH}$ and temperature measurements. Measurements were performed within the first hour post mortem (initial $\mathrm{pH}$ and temperature) and 24 hours after slaughter under refrigeration at $0 \pm 2^{\circ} \mathrm{C}$ (ultimate $\mathrm{pH}$ and temperature).

Color was read on the ventral side of the breast fillet 24 hours post-mortem, at three different points using a colorimeter (Minolta CR10). Meat luminosity ( $\left.L^{*}\right)$, redness $\left(a^{*}\right)$, and yellowness $\left(b^{*}\right)$ values are expressed according to the CIELAB color system.

Water loss by pressure was evaluated in $2 \mathrm{~g}$ of the right breast muscle. The samples were weighed on a semi-analytical scale, placed between two filter sheets (Whatman n.1) and pressed between two acrylic plates under a 10-kg weight for 5 minutes, and then weighed.

The left Pectoralis major muscle was weighed and roasted on a pre-heated electric oven at $180^{\circ} \mathrm{C}$ until reaching $72^{\circ} \mathrm{C}$ internal temperature of (5 minutes on each side). After cooking, samples were cooled at 4 $\pm 2^{\circ} \mathrm{C}$ for 12 hours and weighed again to determine cooking water loss.

The left Pectoralis minor muscle was weighed and frozen for 24 hours; after defrosting, it was weighed again to determine defrosting water loss.

Data were submitted to statistical analysis using the Statistical Analysis System (SAS) at 5\% significance level. Data relative to the incidence of white striping did not present a normal distribution, and therefore were transformed by RANK procedure of SAS, and then submitted to analysis of variance by the GLM procedure of SAS.

\section{RESULTS}

Incubation temperature, breeder age, or broiler sex did not influence ( $p>0.05$ ) had no effect on carcass, breast, or leg yields. However, sex affected abdominal fat percentage (Table 1), with females presenting higher levels $(p<0.05)$ than males, independently of breeder age or of incubation temperature.

Table 1 - Carcass and prime parts yields of male and female broilers derived from 30- and 60-week-old breeders and submitted to different temperatures during incubation.

\begin{tabular}{|c|c|c|c|c|}
\hline \multirow{3}{*}{$\begin{array}{l}\text { Incubation temperature } \\
\text { Normal }\end{array}$} & \multicolumn{4}{|c|}{ Yield, \% } \\
\hline & Carcass & Breast & Leg & Fat \\
\hline & $78.16 \pm 0.17$ & $36.69 \pm 0.49$ & $27.49 \pm 0.48$ & $2.26 \pm 0.11$ \\
\hline Circadian & $77.90 \pm 0.21$ & $37.11 \pm 0.31$ & $26.40 \pm 0.23$ & $2.26 \pm 0.15$ \\
\hline p-value & 0.5661 & 0.6348 & 0.0530 & 0.9969 \\
\hline \multicolumn{5}{|l|}{ Broiler breeder age } \\
\hline 30 & $77.94 \pm 0.17$ & $37.16 \pm 0.27$ & $26.81 \pm 0.22$ & $2.26 \pm 0.14$ \\
\hline 60 & $78.13 \pm 0.21$ & $36.64 \pm 0.52$ & $27.08 \pm 0.50$ & $2.26 \pm 0.13$ \\
\hline p-value & 0.7572 & 0.9001 & 0.6135 & 0.9784 \\
\hline \multicolumn{5}{|l|}{ Sex } \\
\hline Male & $77.93 \pm 0.21$ & $37.02 \pm 0.35$ & $26.90 \pm 0.24$ & $1.85^{b} \pm 0.10$ \\
\hline Female & $78.14 \pm 0.16$ & $36.78 \pm 0.47$ & $26.99 \pm 0.49$ & $2.67^{a} \pm 0.12$ \\
\hline p-value & 0.2063 & 0.9644 & 0.2871 & $<0.0001$ \\
\hline \multicolumn{5}{|l|}{ Interactions } \\
\hline Incubation x Age & 0.1550 & 0.1937 & 0.9384 & 0.2748 \\
\hline Incubation $x$ Sex & 0.3615 & 0.5126 & 0.6866 & 0.7749 \\
\hline Age $\times$ Sex & 0.7970 & 0.5310 & 0.3900 & 0.3097 \\
\hline Incubation $x$ Age $x$ Sex & 0.2668 & 0.4663 & 0.4929 & 0.3042 \\
\hline$C V, \%$ & 1.28 & 4.55 & 4.90 & 28.48 \\
\hline
\end{tabular}


Relative to the measured meat quality parameters, initial and ultimate $\mathrm{pH}$ and temperature values were not affected ( $p>0.05$ ) by the evaluated factors, as shown in Table 2. Cooking, defrosting, and pressing weight loss of the breasts are presented in Table 3, according to incubation temperature, breeder age, and sex. Pressing weight loss was affected by the interaction $(p<0.05)$ between incubation temperature and broiler breeder age. The breakdown of this interaction (Table 4) shows that the meat of the progeny of 30-weekold breeders, when submitted to higher temperature stimuli from 16 to 19 days of incubation, presented greater pressing weight loss than the progeny of older breeders.

Table 2 - Breast meat initial and ultimate $\mathrm{pH}$ and temperature values of male and female broilers derived from 30- and 60 -week-old breeders and submitted to different temperatures during incubation.

\begin{tabular}{|c|c|c|c|c|}
\hline \multirow[b]{2}{*}{ Incubation temperature } & \multicolumn{2}{|c|}{ At slaughter } & \multicolumn{2}{|c|}{24 hours postmortem } \\
\hline & $\mathrm{pH}$ & $\mathrm{T}^{\circ} \mathrm{C}$ & $\mathrm{pH}$ & $\mathrm{T}^{\circ} \mathrm{C}$ \\
\hline Normal & $6.25 \pm 0.07$ & $34.44 \pm 0.46$ & $5.74 \pm 0.05$ & $10.09 \pm 0.37$ \\
\hline Circadian & $6.29 \pm 0.04$ & $34.58 \pm 0.33$ & $5.75 \pm 0.04$ & $9.37 \pm 0.32$ \\
\hline$p$-value & 0.771 & 0.6928 & 0.8132 & 0.3840 \\
\hline \multicolumn{5}{|l|}{ Broiler breeder age } \\
\hline 30 weeks & $6.28 \pm 0.04$ & $34.84 \pm 0.38$ & $5.75 \pm 0.04$ & $9.30 \pm 0.38$ \\
\hline 60 weeks & $6.27 \pm 0.07$ & $34.18 \pm 0.42$ & $5.74 \pm 0.05$ & $10.16 \pm 0.30$ \\
\hline$p$-value & 0.3027 & 0.4777 & 0.6423 & 0.2519 \\
\hline \multicolumn{5}{|l|}{ Sex } \\
\hline Male & $6.34 \pm 0.04$ & $34.43 \pm 0.33$ & $5.78 \pm 0.04$ & $9.61 \pm 0.38$ \\
\hline Female & $6.21 \pm 0.06$ & $34.60 \pm 0.46$ & $5.71 \pm 0.05$ & $9.85 \pm 0.32$ \\
\hline$p$-value & 0.1947 & 0.2906 & 0.3427 & 0.7070 \\
\hline \multicolumn{5}{|l|}{ Interactions } \\
\hline Incubation x Age & 0.7296 & 0.5727 & 0.7572 & 0.4108 \\
\hline Incubation x Sex & 0.7896 & 0.6636 & 0.6742 & 0.4108 \\
\hline Age $x$ Sex & 0.9405 & 0.6161 & 0.8327 & 0.4901 \\
\hline Incubation x Age x Sex & 0.2780 & 0.0840 & 0.9556 & 0.3710 \\
\hline$C V, \%$ & 3.25 & 5.33 & 3.11 & 21.14 \\
\hline
\end{tabular}

Table 3 - Cooking, defrosting, and pressing weight loss of breast meat samples of of male and female broilers derived from 30- and 60-week-old breeders and submitted to different temperatures during incubation.

\begin{tabular}{|c|c|c|c|}
\hline \multirow[b]{2}{*}{ Incubation temperature } & \multicolumn{3}{|c|}{ Loss $\%$} \\
\hline & Cooking & Defrosting & Pressing \\
\hline Normal & $23.25 \pm 0.68$ & $17.53^{\mathrm{a}} \pm 1.71$ & $8.76 \pm 0.56$ \\
\hline Circadian & $22.05 \pm 1.30$ & $15.88^{b} \pm 3.16$ & $12.00 \pm 1.99$ \\
\hline$p$-value & 0.6710 & 0.0591 & 0.5675 \\
\hline \multicolumn{4}{|l|}{ Broiler breeder age } \\
\hline 30 weeks & $21.91 \pm 1.29$ & $15.94 \pm 1.86$ & $10.95 \pm 1.59$ \\
\hline 60 weeks & $23.38 \pm 0.68$ & $17.48 \pm 3.01$ & $9.78 \pm 1.34$ \\
\hline$p$-value & 0.4912 & 0.6738 & 0.2167 \\
\hline \multicolumn{4}{|l|}{ Sex } \\
\hline Male & $23.20 \pm 0.74$ & $13.38 \pm 1.86$ & $11.24 \pm 1.59$ \\
\hline Female & $22.09 \pm 1.26$ & $19.96 \pm 3.16$ & $9.50 \pm 0.67$ \\
\hline p-value & 0.7310 & 0.0887 & 0.2113 \\
\hline \multicolumn{4}{|l|}{ Interactions } \\
\hline Incubation x Age & 0.6007 & 0.5072 & 0.0345 \\
\hline Incubation x Sex & 0.8893 & 0.7087 & 0.6658 \\
\hline Age $x$ Sex & 0.4675 & 0.4528 & 0.7201 \\
\hline Incubation x Age x Sex & 0.1577 & 0.2994 & 0.1896 \\
\hline$C V, \%$ & 18.26 & 58.81 & 34.71 \\
\hline
\end{tabular}

Table 4 - Statistical breakdown of the incubation temperature $\mathrm{x}$ broiler breeder age interaction for pressing weight loss due of broiler breast meat.

\begin{tabular}{llll}
\hline & \multicolumn{2}{c}{ Broiler breeder age } & p value \\
\hline $\begin{array}{llll}\text { Incubation } \\
\text { temperature }\end{array}$ & 30 weeks & 60 weeks & \\
Normal & $8.39^{\mathrm{Aa}}$ & $9.13^{\mathrm{Aa}}$ & 0.5357 \\
Circadian & $10.75^{\mathrm{Aa}}$ & $7.81^{\mathrm{Ba}}$ & 0.0503 \\
$\mathrm{p}$-value & 0.0818 & 0.1935 & \\
\hline
\end{tabular}

Means followed by equal lowercase letters in the same column do not significantly differ ( $p>0.05$ ). Means followed by equal uppercase letters in the same row do not significantly differ $(p>0.05)$.

Table 5 shows that there were no effects $(p>0.05)$ of incubation temperature or breeder age, on meat luminosity $\left(L^{*}\right)$, redness $\left(a^{*}\right)$, or yellowness $\left(b^{*}\right)$ values. However, higher redness values $(p<0.05)$ were observed in the breast meat of females than in males. The presence white striping on the breast was not significantly influenced ( $p>0.05$ ) by the evaluated factors. 
Table 5 - Meat color measurements ( $L^{*}, a^{*}$ e $b^{*}$ values) and the incidence of white striping on the breast of of male and female broilers derived from 30- and 60-week-old breeders and submitted to different temperatures during incubation.

\begin{tabular}{|c|c|c|c|c|c|}
\hline \multirow[b]{2}{*}{ Incubation temperature } & \multicolumn{3}{|c|}{ Color } & \multicolumn{2}{|c|}{ White striping, \% } \\
\hline & $\mathrm{L}$ & $a$ & $\mathrm{~b}$ & No & Yes \\
\hline Normal & $57.50 \pm 0.54$ & $1.91 \pm 0.22$ & $12.97 \pm 0.36$ & 31.25 & 68.75 \\
\hline Circadian & $57.80 \pm 0.60$ & $1.86 \pm 0.18$ & $12.86 \pm 0.41$ & 28.13 & 71.88 \\
\hline$p$-value & 0.7195 & 0.8482 & 0.8534 & & \\
\hline \multicolumn{6}{|l|}{ Broiler breeder age } \\
\hline 30 weeks & $57.96 \pm 0.57$ & $1.71 \pm 0.18$ & $12.78 \pm 0.38$ & 34.38 & 65.63 \\
\hline 60 weeks & $57.34 \pm 0.57$ & $2.06 \pm 0.22$ & $13.05 \pm 0.38$ & 25.00 & 75.00 \\
\hline p-value & 0.4653 & 0.2181 & 0.6227 & \multicolumn{2}{|c|}{0.4237} \\
\hline \multicolumn{6}{|l|}{ Sex } \\
\hline Male & $58.02 \pm 0.54$ & $1.52^{b} \pm 0.17$ & $12.84 \pm 0.40$ & 31.25 & 68.75 \\
\hline Female & $57.28 \pm 0.60$ & $2.25^{\mathrm{a}} \pm 0.21$ & $12.99 \pm 0.37$ & 28.13 & 71.88 \\
\hline$p$-value & 0.3803 & 0.0130 & 0.7967 & \multicolumn{2}{|c|}{0.7892} \\
\hline \multicolumn{6}{|l|}{ Interactions } \\
\hline Incubation $\times$ Age & 0.3145 & 0.8036 & 0.3464 & \multicolumn{2}{|c|}{0.7892} \\
\hline Incubation x Sex & 0.8466 & 0.5085 & 0.4746 & \multicolumn{2}{|c|}{0.4237} \\
\hline Age $x$ Sex & 0.6171 & 0.8244 & 0.1613 & \multicolumn{2}{|c|}{0.0653} \\
\hline Incubation x Age $x$ Sex & 0.6927 & 0.4844 & 0.7770 & \multicolumn{2}{|c|}{0.4237} \\
\hline$C V, \%$ & 5.80 & 60.05 & 17.34 & \multicolumn{2}{|c|}{45.81} \\
\hline
\end{tabular}

\section{DISCUSSION}

The present trial was to evaluate the effect of increasing incubation temperature $\left(38.2-38.4^{\circ} \mathrm{C}\right.$ for 4 hours/d on days 16 to 19 of incubation) on the meat yield and quality of broiler submitted to heat stress during the last two days of rearing. Our hypothesis was that circadian incubation could induce embryo training or imprinting by early acclimation of the thermoregulatory system, allowing the broilers to cope better with heat stress. However, increasing incubation temperature at the end of incubation did not affect carcass yield prime parts yields of broilers subsequently submitted to heat stress. This result is not in agreement with those reported in literature. Collin et al. (2007) and Piestun et al. (2008) obtained heavier breast muscles when broiler embryos were incubated at high intermittent temperature $\left(3 \mathrm{~h}, 39.5^{\circ} \mathrm{C}, 16\right.$ to 18 days of incubation).

Females presented greater fat deposition than males. According to Mendes \& Komiyama (2011), females have specific physiological processes for reproductive activity, leading to a greater accumulation of fat that increases with advanced age, thereby bringing losses in meat carcass yield.

Halle \& Tzschentke (2010) observed that incubation at high temperatures caused long-term changes in body functions and improved acclimation to heat.

Variations in meat color are associated with differences in muscle myoglobin content, morphology, and $\mathrm{pH}$ (Mendes \& Komiyama, 2011). As observed in
Table 2, females presented meat higher redness values $\left(a^{*}\right)$, which is directly related to myoglobin content in the muscle, indicating higher post-mortem glycolysis rate, which results in muscle color change (McKee \& Sams, 1997). Abreu et al. (2014) also observed that the meat of female quails is redder than that of males. The reason for this difference between female and male broilers remains to be determined in future experiments.

It is known that male broilers are more vulnerable to environmental changes than females (Bogdanova \& Nager, 2008). However, in the present trial, the meat quality of neither male or female broilers was affected by the high incubation temperature applied during the sensitive period of embryonic thermoregulatory system development. On the other hand, Ferreira et al. (2015) showed that high incubation temperatures increased chicken meat toughness (shear force) and reduced meat redness values, but did not change meat cooking loss, $\mathrm{pH}$, or luminosity.

Appearance is an important meat quality characteristic related to the acceptance or rejection of products by consumers. One of the factors that affects chicken meat appearance is water retention capacity (Garcia et al., 2012), particularly during storage (Berri et al., 2005; Tona et al., 2008). It is known the effect of breeder age influences the live performance of their progeny (Peebles et al., 1999). When the embryos were submitted to high temperatures between 16 and 19 days of incubation, the meat of broilers derived from 30-wk-old breeders presented higher pressure weight 
Fernandes JIM, Santos TC, Kaneko IN, Horn D, Leyter JR, Pasa CLB

\section{Effect of Thermal Embryonic Manipulation on the Quality of Male and Female Broiler Meat Submitted to Thermal Stress Pre-Slaughter}

loss compared with those from 60-wk-old breeders. This effect may be explained by the higher nutritional content and more balanced nutrient profile of the yolk of the eggs laid by old breeders, promoting uscle development and enhancing the functional properties of broiler meat.

Yalçin et al. (2005) investigated the relationship between broiler breeder age breeders and the effectiveness of pre-and postnatal conditioning induced thermal tolerance. According to those researchers, although pre- and postnatal conditioning may help broilers cope with heat stress during grow-out, breeder age has a strong influence on the thermoregulation ability of broilers. Thermal conditioning of embryos and additional conditioning the chicks thereafter may eliminate or at least reduce the adverse effects of heat stress on broilers from younger parents. The possible interference of breeder nutrition with these mechanisms remains to be explored.

Although the numerical increase in the incidence of white striping on the breasts of the progeny of older breeders was not statistically significant, this trend warrants further investigation. According to Yalçin et al. (2005), breeder age plays an important role in the response of the embryo temperature manipulation during incubation; this may influence the performance during the post egg-hatching period. Nevertheless, no references on the influence of breeder age on the incidence of that myopathy in the progeny were found in literature.

The efforts to increase the body weight of broilers should not be limited to management and care during the post-hatching period. Incubation factors that affect broiler performance should also be determined. Circadian incubation has been evaluated as an alternative to induce phenotypes adapted to different rearing environments, and that therefore could present adequate live performance and meat quality under adverse environmental conditions.

Thermal manipulation during incubation failed to improve the thermal tolerance of broilers submitted to heat stress during the pre-slaughter period. This may be due to a lowe degree of thermal stimulation and/ or short duration of thermal stimulation. However, it is also possible that thermal stimulation was not applied during the optimal sensitive period (Collin et al., 2007; Tona et al., 2008) in the present study. This warrants further research on the optimal conditions for thermal manipulation.

Another hypothesis is that an additional stimulation is required to obtain long-term thermal tolerance. In a recent study, Ferreira et al (2015) reported that high incubation temperature during the embryonic phase plus in-ovo vitamin $C$ injection prevented the thermal stress effects of high rearing temperatures.

In addition, optimal embryo requirements regarding incubation temperature, relative humidity, and $\mathrm{CO}_{2}$ concentration to obtain maximum hatchability, hatchling quality, and subsequent thermal tolerance are still not completely known. Therefore, studies on the thermal manipulation of chick embryos must consider the influence of all these parameters on longer-lasting thermoregulatory responses and on the acquisition of thermal tolerance.

The results showed that incubation temperature manipulation during the final incubation phase (16 to 19 days/4 hours daily) did not influence the meat yield or meat quality of male and female broilers submitted to heat stress before slaughter.

\section{REFERENCES}

Abreu LRA, Boari CA, Pires AV, Pires SRF, Oliveira RG, Oliveira KM, et al. Influência do sexo e idade de abate sobre rendimento de carcaça e qualidade da carne de codornas de corte. Revista Brasileira de Saúde e Produção Animal 2014;15(1):131-140.

Aksit M, Yalçin S, Yenisey C, Ozdemir DB. Brooding temperatures for chicks acclimated to heat during incubation: effects on post-hatch intestinal development and body weight under heat stress. Poultry Science 2010;51(3):444-452.

Berri C, Debut M, Santé-Lhoutellier V, Arnould C, Boutten B, Sellier N, et al. Variations in chicken breast meat quality:Implications of struggle and muscle glycogen content at death. British Poultry Science 2005;46(5):572-579.

Boerjan M. Circadian incubation for robustness. Proceeding of the $12^{\text {a }}$ European Poultry Congress; 2010 Aug 23-27; Tours, France.

Bogdanova Ml, Nager RG. Sex-specific costs of hatching last:An experimental study on herring gulls (Larusargentatus). Behavioral Ecology and Sociobiology 2008;62:1533-1541.

Cobb. Manual de manejo de frangos de corte. 2008 [cited 2015 Nov 18]. Available from: http://wp.ufpel.edu.br/avicultura/files/2012/04/CobbManual-Frango-Corte-BR.pdf.

Collin A, Berri C, Tesseraud S, Requena Rodin FE, Skiba-Cassy S, Crochet $S$, et al. Effects of thermal manipulation during early and late embryogenesis on thermotolerance and breast muscle characteristics in broiler chickens. Poultry Science 2007;86:795-800.

Collin A, Picard M, Yahav S. The effects of duration of thermal manipulation during broiler chick embryogenesis on body weight and body temperature of post-hatched chicks. Animal Research 2005;54:105111.

Ferreira IB, Matos Junior JB, Sgavioli S, Vicentini TI, Morita VS, Boleli IC. Vitamin $C$ prevents the effects of high rearing temperatures on the quality of broiler thigh meat. Poultry Science 2015;94(5):841-851.

Garcia RG. Qualidade de filés de peito de frango de corte marinados e maturados. Revista Agrarian 2012;5(16):166-173. 
Halevy O, Krispin A, Leshem Y, Mcmurtry JP, Yahav S. Early age heat exposure affects skeletal muscle satellite cell proliferation and differentiation in chicks. American Journal of Physiology-Regulatory Integrative and Comparative Physiology 2001;281:302-309.

Halevy O, Yahav S, Rozenboim I. Enhancement of meat production by environmental manipulations in embryo and young broilers. World's Poultry Science Journal 2006;62:485-497.

Halle I, Tzschentke B. Influence of temperature manipulation during the last 4 days of incubation on hatching results, post-hatching performance and adaptability to warm growing conditions in broiler chickens. Journal Poultry Science 2010;48:97-105.

Hamidu JA, Fasenko GM, Feddes JJR, O'dea EE, Ouellette CA, Wineland $M J$, et al. The effect of broiler breeder genetic strain and parent flock age on eggshell conductance and embryonic metabolism. Poultry Science 2007;86:2420-2432

Hulet R, Gladys G, Hill D, Meijerhof R, EL Shiekh T. Influence of eggs hell embryonic incubation temperature and broiler breeder flock age on posthatch growth performance and carcass characteristics. Poultry Science 2007;86:408-412.

Maltby V, Somaiya A, French NA, Stickland NC. In ovo temperature manipulation influences posthatch muscle growth in the turkey. British Poultry Science 2004;45:491-498.

McKee SR, Sams AR. The effect of seasonal heat stress on rigor development and the incidence of pale, exudative turkey meat. Poultry Science 1997;76:1616-1620.

Mendes AA, Komiyama CM. Estratégias de manejo de frangos de corte visando qualidade de carcaça e carne. Revista Brasileira de Zootecnia 2011;40:352-357.

Molenaar R, Reijrink IAM, Meijerhof R, Van den Brand $H$. Meeting embryonic requirements of broilers throughout incubation:a review. Revista Brasileira de Ciência Avícola 2010;12(3):137-148.

Moraes VMB, Malheiros RD, Bruggeman V, Collin A, Tona K, Van As P, et al. The effect of timing of thermal conditioning during incubation on embryo physiological parameters and its relationship to thermotolerance in adult broiler chickens. Journal of Thermal Biology 2004;29(1):55-61.
Peebles ED, Doyle SM, Pansky T, Gerard PD, Latour MA, Boyle CR, et al. Effects of breeder age and dietary fat on subsequent broiler performance. 2. Slaughter yield. Poultry Science 1999;78(4):512-515.

Petracci M, Cavani C. Muscle growth and poultry meat quality issues. Nutrients 2012;4:1-12.

Piestun Y, Shinder D, Ruzal M, Halevy O, Brake J, Yahav S. Thermal manipulations during broiler embryogenesis:e effect on the acquisition of thermotolerance. Poultry Science 2008;87:1516-1525.

Tona K, Onagbesan O, Bruggeman V, Collin A, Berri C, Duclos MJ, et al. Effects of heat conditioning at $d 16$ to 18 of incubation or during early broiler rearing on embryo physiology, post-hatch growth performance and heat tolerance. Archives für Geflügelkunde 2008;72:75-83.

Tzschentke B, Plagemann A. Imprinting and critical periods in early development. World's Poultry Science Journal 2006;62:626-637.

Tzschentke B, Halle I. Influence of temperature stimulation during the last 4 days of incubation on secondary sex ratio and later performance in male and female broiler chicks. British Poultry Science 2009;50:634640 .

Yahav S, Sasson RR, Shinder D. The effect of thermal manipulations during embryogenesis of broiler chicks (Gallus domesticus) on hatchability, body weight and thermoregulation after hatch. Journal Thermal Biology 2004;29:245-250.

Yalçin S, Zkan SO, Abuk MC, Buyse J, Decuypere E, Siegel PB. Pre- and postnatal conditioning induced thermotolerance on body weight, physiological responses and relative asymmetry of broilers originating from young and old breeder flocks. Poultry Science 2005;84:967-976.

Yalçin S, Çabuk M, Bruggeman V, Babacanoglu E, Buyse J, Decuypere E, et al. Acclimation to heat during incubation:3. Body weight, cloacal temperatures, and blood acid-base balance in broilers exposed to daily high temperatures. Poultry Science 2008;87:2671-2677.

Yalçin S, Siegel PB. Exposure to cold or heat during incubation on developmental stability of broiler embryos. Poultry Science 2003;82:1388-1392. 
